\title{
Pressure, Isotope, and Water Co-solvent Effects in Liquid-Liquid Equilibria of (Ionic Liquid + Alcohol) Systems
}

\author{
Vesna Najdanovic-Visak, ${ }^{\dagger}$ José M. S. S. Esperança, ${ }^{\ddagger}$ Luís P. N. Rebelo, $*, \dagger$ \\ Manuel Nunes da Ponte, ${ }^{\dagger}$ Henrique J. R. Guedes, $₫$ Kenneth R. Seddon, $₫$ \\ Hermínio C. de Sousa, ${ }^{\#}$ and Jerzy Szydlowski ${ }^{\dagger, \perp}$ \\ Instituto de Tecnologia Química e Biológica, Universidade Nova de Lisboa, Apartado 127, \\ 2780-901 Oeiras, Portugal, REQUIMTE, Departamento de Quimica, FCT, Universidade Nova de Lisboa, \\ 2829-516 Caparica, Portugal, The QUILL Centre, The Queen's University of Belfast, Stranmillis Road, \\ Belfast BT9 5AG, United Kingdom, and Departamento de Engenharia Química, FCT, Universidade de \\ Coimbra, Polo II-Pinhal de Marrocos, 3030-290 Coimbra, Portugal
}

Received: March 6, 2003; In Final Form: August 14, 2003

\begin{abstract}
Liquid-liquid phase splitting in ternary mixtures that contain a room-temperature ionic liquid and an alcohol aqueous solution-namely, $[\mathrm{bmim}]\left[\mathrm{PF}_{6}\right]+$ ethanol + water and $[$ bmim $]\left[\mathrm{NTf}_{2}\right]+2$-methylpropanol + wateris studied. Experimental cloud-point temperatures were obtained up to pressures of 400 bar, using a $\mathrm{He}-\mathrm{Ne}$ laser light-scattering technique. Although pressurization favors mutual miscibility in the presence of high concentrations of alcohols, the contrary occurs in water-rich solutions. Both ternary mixtures exhibit a very pronounced water-alcohol co-solvent effect. Solvent isotope effects are also investigated. Phase diagrams are discussed using a phenomenological approach based on a "polymer-like" $G^{\mathrm{E}}$ model coupled with the statistical-mechanical theory of isotope effects. The combined effect of a red shift of $-15 \mathrm{~cm}^{-1}$ for the $\mathrm{O}-\mathrm{H}$ deformation mode of ethanol with a blue shift of $+35 \mathrm{~cm}^{-1}$ for the $\mathrm{O}-\mathrm{H}$ stretching mode, both of which occurring after liquid infinite dilution in the ionic liquid, rationalizes the observed isotope effect in the phase diagram. Predicted excess enthalpy $\left(H^{\mathrm{E}}\right)$ values are inferred from the model parameters. Furthermore, using the Prigogine-Defay equation, an estimation of the excess volumes $\left(V^{\mathrm{E}}\right)$ is obtained.
\end{abstract}

\section{Introduction}

Molten salts that are stable liquids at and near room temperature, which present a nonmeasurable (infinitesimally small) vapor pressure and are generally considered to be environmentally benign, are, obviously, extremely attractive as alternative solvents. However, despite the increasing attention that this class of room-temperature ionic liquids (RTILs) has recently deserved, in regard to their use in synthesis and catalysis, very little about their phase behavior in solution is known. ${ }^{1}$ Basically, chemical and chemistry-related issues that arise because of this new generation of solvents have grown much faster than their fundamental thermophysical counterparts.

Within the RTIL class of compounds, those that are based on the cation 1-butyl-3-methylimidazolium $\left([\mathrm{bmim}]^{+}\right.$) are among the most popular and commonly used. Hexafluorophosphate $\left(\left[\mathrm{PF}_{6}\right]^{-}\right)$-based RTIL is historically the most important and the most commonly investigated RTIL compound. We have thus chosen $[\mathrm{bmim}]\left[\mathrm{PF}_{6}\right]$ for our studies. However, $\left[\mathrm{PF}_{6}\right]^{-}$seems to be harmful; it can produce HF, when in contact with water, ${ }^{2}$ mainly at high temperatures. ${ }^{3}$ Therefore, an alternative anion has also been considered: bis(trifluoromethylsulfonyl)amide

* Author to whom correspondence should be addressed. E-mail: luis.rebelo@itqb.unl.pt.

† Instituto de Tecnologia Química e Biólogica, Universidade Nova de Lisboa.

Departamento de Química, FCT, Universidade Nova de Lisboa.

$\S$ The Queen's University of Belfast.

\# Universidade de Coimbra.

${ }^{\perp}$ Permanent address: Chemistry Department, Warsaw University, Zwirki I Wigury 101, 02-089 Warsaw, Poland.
$\left(\left[\mathrm{N}\left\{\mathrm{SO}_{2}\left(\mathrm{CF}_{3}\right)\right\}_{2}\right]^{-}\right.$, or $\left.\left[\mathrm{NTf}_{2}\right]^{-}\right)$. RTILs also show great potential as possible extractants of a wide variety of components in aqueous solution media. In particular, they eventually may have an important role in the recovery of butanol and ethanol that are produced in fermentation processes. ${ }^{4}$ The current study focuses on solutions of $[\mathrm{bmim}]\left[\mathrm{PF}_{6}\right]+$ ethanol $(\mathrm{EtOH})$ and/or water, as well as those of $[\mathrm{bmim}]\left[\mathrm{NTf}_{2}\right]+2$-methylpropanol $(i-\mathrm{BuOH})$ and/or water, because they present partial immiscibility not far from room temperature, thus making such compounds attractive, from a technological perspective.

In the search for a more comprehensive understanding of the phase behavior of RTIL solutions, we have followed the phasediagram shifts as a function of pressure and isotope effects. Phase diagrams will be discussed using a phenomenological approach based on a Flory-Huggins-like $G^{\mathrm{E}}$-model,${ }^{5}$ coupled with the statistical-mechanical theory of isotope effects. ${ }^{6}$

\section{Experimental Section}

2.1. Chemicals and Preparation of Solutions. $[\mathrm{bmim}]\left[\mathrm{PF}_{6}\right]$ and $[\mathrm{bmim}]\left[\mathrm{NTf}_{2}\right]$ were synthesized and purified at the QUILL Centre in Belfast, according to recipes found elsewhere. ${ }^{7}$ They were washed several times with water, to decrease the chloride content. It was confirmed that no precipitation (of $\mathrm{AgCl}$ ) would occur by adding $\mathrm{AgNO}_{3}$ to the wash water. Their purity (estimated at $99.8 \%$ ) was checked using NMR spectroscopy. A vacuum and moderate temperature $\left(60^{\circ} \mathrm{C}\right)$ were applied to the RTIL samples for several days, to reduce the water content to a value that was negligible for the present purposes. Fresh samples were always used in the preparation of solutions of both RTILs, to determine the phase diagrams. Therefore, RTILs 
have never been recovered and reused. High-quality ethanol (a maximum water content of $0.02 \%$, as claimed by the manufacturer) was purchased from Panreac and 2-methylpropanol (with $>99.0 \%$ purity) was purchased from Riedel-de-Haen. Both solvents were further dried with $3 \AA$ molecular sieves. Monodeuterated ethanol $\left(\mathrm{CH}_{3} \mathrm{CH}_{2} \mathrm{OD}\right.$, with $>99.5$ at. \% D), from Aldrich, was also dried further with $3 \AA$ molecular sieves. Although we have not performed any direct analysis of the water content of any of the alcohols, we have assumed that the treatment with molecular sieves has reduced the water content to sufficiently low and similar (between ethanol and its monodeuterated counterpart) values, so far as to avoid any effects on the isotope effect measurements. Water was distilled and deionized using a Milli-Q water filtration system from Millipore. All liquid solutions were gravimetrically prepared to an estimated uncertainty of $0.02 \%$ for a typical nondiluted mass percentage.

2.2. Equipment and Methodology. A He-Ne laser lightscattering cell was used for the accurate detection of cloud points. The apparatus, as well as the methodology used for the determination of phase transitions, have recently been described in detail ${ }^{8}$ however, only a brief description is provided here. The cell (with an internal volume of $\sim 1.0 \mathrm{~cm}^{3}$ and an optical length of $\sim 2.6 \mathrm{~mm}$ ) is a thick-walled Pyrex glass tube that is connected to a pressurization line and separated from it by a mercury plug. The intensity of the scattered light is captured at a very low angle $\left(2^{\circ}<2 \theta<4^{\circ}\right)$ in the outer portion of a bifurcated optical cable, ${ }^{9}$ whereas transmitted light is captured in the inner portion of this cable. The intensity of scattered light $\left(I_{\mathrm{sc}}\right)$ and transmitted light $\left(I_{\mathrm{tr}}\right)$ are corrected for density fluctuations, reflections, and multiple scattering effects. The cloud point is the point on the least-squares fits of $\left(I_{\mathrm{sc}, \mathrm{corr}}\right)^{-1}$ against pressure $(P)$ or temperature $(T)$ where the slope changes abruptly. The cloud-point temperature accuracy is typically $\pm 0.01 \mathrm{~K}$ in the range of $240 \mathrm{~K}<T<400 \mathrm{~K}$. We used a Hart Scientific calibration bath with a stability of $\pm 1 \mathrm{~m} \mathrm{~K}$ within the working temperature range and a four-wire PRT 100 system that was connected to a $6^{1 / 2}$ digit multimeter to display the thermometer's resistance. The claimed accuracy $( \pm 0.01 \mathrm{~K})$ can be confirmed either by reproducing some individual experimental datum points or by statistical analysis of the calibration curve provided by the manufacturer. In regard to pressure, the accuracy is \pm 0.1 bar, up to a pressure of 50 bar. This value is the upper limit of pressure for the glass capillary cell.

For experiments where the pressure was increased to $>50$ bar (and up to 500 bar), a novel sapphire/stainless-steel cell ${ }^{10}$ replaced the original glass capillary cell. In this case, the hydraulic fluid is the pure solvent (in this work, water or alcohol) that is in contact with a sufficiently long $(1 / 16)$-in. stainlesssteel tube filled with the solution (buffer volume), to avoid contamination during compression/expansion cycles. The total volume (buffer + optical) of injected solution is typically 1.6 $\mathrm{cm}^{3}$, although the optical volume approximately corresponds to a mere $0.5 \mathrm{~cm}^{3}$. In the case of isothermal runs, the cloudpoint temperature accuracy was maintained $( \pm 0.01 \mathrm{~K})$ but worsens slightly for isobaric runs. In regard to pressure, the uncertainty is \pm 1 bar in this higher-pressure range.

For both cells, one can operate either in the isobaric or isothermal mode. Abrupt changes in either the least-squares fit of transmitted or scattered light versus temperature or pressure upon phase transition sharpen as the thermodynamic path approaches an angle perpendicular to the one-phase/two-phase surface. For the particular characteristics of the current systems
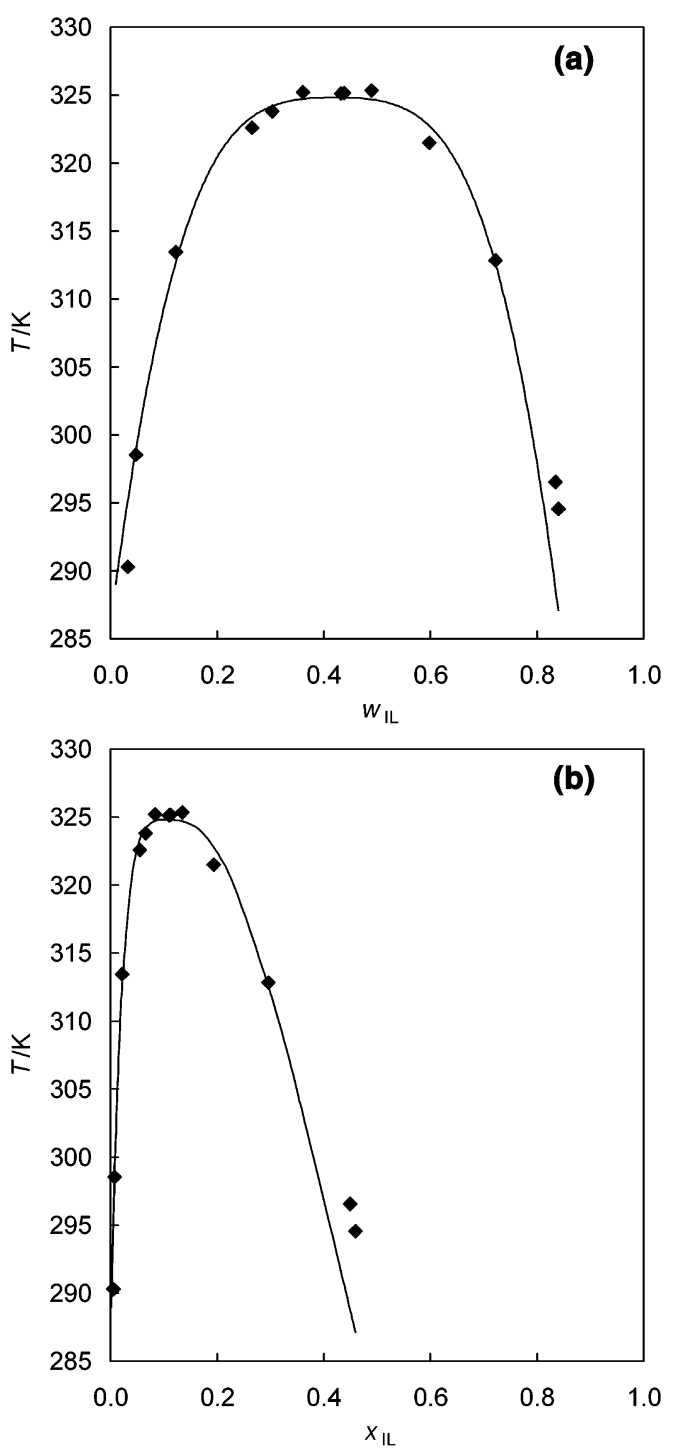

Figure 1. Atmospheric-pressure phase diagram of binary liquid ([bmim $]\left[\mathrm{PF}_{6}\right]+$ ethanol) mixtures using two different field variables: (a) mass fraction $\left(w_{\mathrm{IL}}\right)$ and $(\mathrm{b})$ mole $\left(x_{\mathrm{IL}}\right)$ fraction of $[\mathrm{bmim}]\left[\mathrm{PF}_{6}\right]$. Solid lines represent least-squares fits to experimental data (denoted by solid diamond symbols), using the scaling-type eq 1. Parameters are reported in Table 3. The two-phase region is located inside the envelope defined by the line.

(see below), that situation is achieved by the isobaric path; thus, cloud points were detected when the temperature was decreased at each selected nominal pressure.

\section{Results and Discussion}

3.1. Phase Diagrams and Their Pressure, Isotope, and Water Co-solvent Effects. Figure 1 depicts the atmospheric pressure phase behavior of mixtures of $[\mathrm{bmim}]\left[\mathrm{PF}_{6}\right]+$ ethanol using two different field variables: mass and mole fractions. Although, in the first case, the phase diagram is almost symmetrical, one obtains an equilibrium line well-skewed to the low-mole fraction side of RTIL in the latter representation. In a previous contribution, ${ }^{3}$ we showed preliminary results for this same system plus that for water as a solvent and the very interestingly large co-solvent effect when water is added to ethanol to form a mixed solvent. A more comprehensive study of this co-solvent effect is now presented in Figure 2 as cloud points obtained along three distinct nonconstant concentrations of RTIL paths. In all three cases, the minimum in the cloud- 


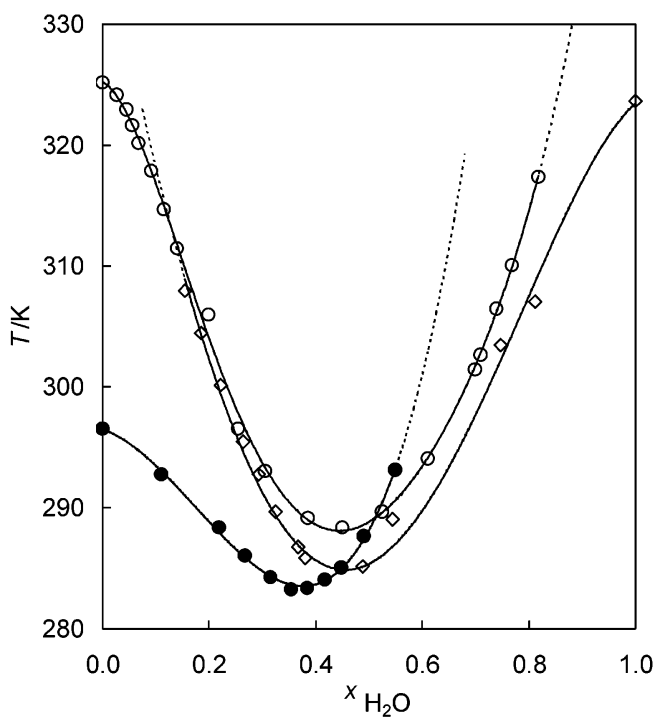

Figure 2. Effect of the addition of water on the $(\bigcirc)$ near-critical and $(\bullet)$ off-critical temperature of transition and $(\diamond)$ that of the addition of ethanol of the liquid $[\mathrm{bmim}]\left[\mathrm{PF}_{6}\right]+\left[x \mathrm{H}_{2} \mathrm{O}+(1-x) \mathrm{CH}_{3} \mathrm{CH}_{2} \mathrm{OH}\right]$ ( $x$ represents the mole fraction of water in the mixed solvent). Lines are drawn as guides to the data.

point temperature is obtained not far from a 1:1 (mole) relation between the quantities of ethanol and water. The overall set of 73 cloud-point data points for $[$ bmim $]\left[\mathrm{PF}_{6}\right]+$ ethanol + water at atmospheric pressure, presented in Table 1 , permits us to construct the ternary phase diagram plotted in Figure 3 for three temperatures. Pressure effects, although relatively modest, also show interesting behavior. Although, in the case of $[\mathrm{bmim}]\left[\mathrm{PF}_{6}\right]$ + ethanol, increasing the pressure helps the mutual solubility (approximately; the transition temperature decreases by $2 \mathrm{~K}$ per each 100 bar), in contrast, miscibility worsens as pressure increases when water is the solvent. Although the current work seems to be the first where pressure effects on the liquid-liquid equilibrium for ionic liquids are considered, this type of response is perhaps more general. Note that another ionic liquid investigated in this work ([bmim] $\left.\left[\mathrm{NTf}_{2}\right]\right)$ also shows a negative $\mathrm{d} T / \mathrm{d} p$ relationship with an alcohol (2-methylpropanol). (See Table 2.) In contrast, a preliminary experimental and theoretical analysis performed on a third RTIL ([bmim] $\left[\mathrm{BF}_{4}\right]$; see Section 3.3, "Phenomenological Model and the Prigogine-Defay Equation") suggests, again, a positive slope for the critical line when water is the solvent. The behavior of the pseudo-binary mixture $[$ bmim $]\left[\mathrm{PF}_{6}\right]+(0.5$ ethanol +0.5 water $)$ is basically unaffected by pressure. This is clearly shown in Figure 4. In the case of $[$ bmim $]\left[\mathrm{PF}_{6}\right]+$ ethanol, we monitored both the pressure dependence of near-critical and off-critical concentrations of RTIL. Interestingly, a plot of $\mathrm{d} T / \mathrm{d} p$ versus $w_{\mathrm{IL}}$ (Figure 5) shows a good degree of similarity for a broad range of concentrations centered on the critical one and milder pressure dependence at more-extreme concentrations. This translates to a tendency for the phase diagram to flatten as the pressure increases. A similar study cannot be performed for water as solvent, because of the almost total immiscibility of this system.

$\mathrm{H} / \mathrm{D}$ isotope effects on the $-\mathrm{OH}$ group of ethanol were also analyzed. Deuteriation slightly improves the miscibility of [bmim] $\left[\mathrm{PF}_{6}\right]$, provoking a downward shift on the transition temperatures of $\sim 1.1 \mathrm{~K}$. This contrasts with the commonly found decrease of mutual miscibility upon $\mathrm{OH}$ deuteriation. ${ }^{6 \mathrm{~b}, 11}$ The pressure dependence of $[\mathrm{bmim}]\left[\mathrm{PF}_{6}\right]+$ ethanol mixtures is quite similar to that of $[\mathrm{bmim}]\left[\mathrm{PF}_{6}\right]+d_{1}$-ethanol mixtures (see Figure 5).
Figure 6 shows the phase diagram of $[\mathrm{bmim}]\left[\mathrm{NTf}_{2}\right]+$ 2-methylpropanol. In consonance with the case of [bmim] $\left[\mathrm{PF}_{6}\right]$ + ethanol, when the mole fraction is used as the field variable, the phases in equilibrium are displaced to the low-mole-fraction side of the RTIL. Also, the addition of water (which is a much worse solvent than 2-methylpropanol) significantly improves the mutual miscibility (Figure 7). Again, water has proven to have a very strong co-solvent effect in this type of mixture. However, the minimum transition temperature is found at a water/2-methylpropanol ratio of $\sim 1: 2$ (mole). The $T-p$ slope of the transition lines, although again negative for this other $\mathrm{RTIL}+$ alcohol, are $\sim 10$ times less pronounced $(-0.25 \mathrm{~K}$ for each 100 bar), in comparison with those of $\left[\mathrm{bmim}^{2}\left[\mathrm{PF}_{6}\right]+\right.$ ethanol. The details of all the aforementioned information on this system are reported in Table 2.

To rationalize the data with the aim of permitting interpolation or extrapolation of the phase diagrams and approximate determination of the critical coordinates, $T_{\mathrm{c}} ; w_{\mathrm{c}}$, scaling-type equations of the following type ${ }^{12}$ have been applied to $[\mathrm{bmim}]\left[\mathrm{PF}_{6}\right]+$ ethanol and $[$ bmim $]\left[\mathrm{NTf}_{2}\right]+2$-methylpropanol:

$$
\left|w-w_{\mathrm{c}}\right|=A\left(\frac{T_{\mathrm{c}}-T}{T_{\mathrm{c}}}\right)^{\beta}
$$

The parameters for a nominal pressure of 1 bar are reported in Table 3 and should be considered as mere fitting parameters, without any significance, in terms of critical phenomena.

Before we close this section, a comment about the water content of both the RTILs and the alcohols is pertinent. As previously stated, no direct determination of the amount of water present in both the RTILs and alcohols was performed. Nonetheless, a detailed analysis of the data shown in Figures 2 and 7 (and reported in Tables 1 and 2) permits us to estimate that amount quantitatively. It should be noted that, irrespective of the solution considered, the plots show a clear curvature in the limit $x_{\mathrm{H}_{2} \mathrm{O}} \rightarrow 0$, whereas they present a fairly linear trend for points with greater mole fractions of water. We attribute this curvature to the presence of a small, but not negligible, amount of water in either the RTIL, the alcohol, or both. In other words, the first datum point on the left side of the diagrams is not effectively located at $x_{\mathrm{H}_{2} \mathrm{O}}=0$ but at some slightly greater value, because either the RTIL and/or the alcohol already contained water. That value is established by forcing the continuation of the linear trend to the limit $x_{\mathrm{H}_{2} \mathrm{O}} \rightarrow 0$. In the case represented by Figure 7 , it seems reasonable to attribute any possible contamination with water to the RTIL, because alcohols with a relatively long alkyl chain (such as 2-methylpropanol) are not particularly hydrophilic. Thus, one obtains an estimated contamination of the $[\mathrm{bmim}]\left[\mathrm{NTf}_{2}\right]$ by water of $0.36 \pm 0.04$ mass \%. The case reported in Figure 2 presents the additional complication that both the RTIL and ethanol are potentially contaminated with water. On the other hand, two solutions (the near- and off-critical concentrations) can be analyzed, and, thus, two data sets can be treated, which permits us to estimate the initial amount of water contamination in both the $[\mathrm{bmim}]\left[\mathrm{PF}_{6}\right]$ and ethanol, using a system of two unknowns and two equations. The results yielded $0.08 \pm 0.03$ mass $\%$ and $0.40 \pm 0.04$ mass $\%$, respectively, of initial water in the [bmim] $\left[\mathrm{PF}_{6}\right]$ and ethanol.

The same data analysis shows that, if, for instance, it were possible to dry the samples of RTILs and alcohols completely, the critical demixing of $[\mathrm{bmim}]\left[\mathrm{PF}_{6}\right]+$ ethanol would occur at ca. $0.7-0.8 \mathrm{~K}$ above the current reported values.

3.2. Brief Review of Available Information on the Same or Similar Systems. To the best of the authors' knowledge, 
12800 J. Phys. Chem. B, Vol. 107, No. 46, 2003

Najdanovic-Visak et al.

TABLE 1: Cloud-Point Data and Their Pressure Dependence for $[\mathrm{bmim}]\left[\mathrm{PF}_{6}\right]+$ Ethanol $\left(-h /-d_{1}\right)+\mathrm{Water}^{a}$

\begin{tabular}{|c|c|c|c|c|c|c|c|c|c|}
\hline$p$ (bar) & $T(\mathrm{~K})$ & $10^{2} w_{\mathrm{IL}}$ & $10^{2} w_{\mathrm{H}_{2} \mathrm{O}}$ & $10^{2} \mathrm{~d} T / \mathrm{d} p(\mathrm{~K} / \mathrm{bar})$ & $p$ (bar) & $T(\mathrm{~K})$ & $10^{2} w_{\mathrm{IL}}$ & $10^{2} w_{\mathrm{H}_{2} \mathrm{O}}$ & $10^{2} \mathrm{~d} T / \mathrm{d} p(\mathrm{~K} / \mathrm{bar})$ \\
\hline \multicolumn{5}{|c|}{$[\mathrm{bmim}]\left[\mathrm{PF}_{6}\right]+$ ethanol } & \multicolumn{5}{|c|}{$[\mathrm{bmim}]\left[\mathrm{PF}_{6}\right]+$ water } \\
\hline 108.50 & 288.66 & \multirow[t]{4}{*}{3.30} & \multirow[t]{4}{*}{0} & \multirow[t]{4}{*}{-1.51} & 1.00 & 284.75 & 1.53 & 100 & \\
\hline 201.30 & 287.35 & & & & 1.00 & 291.15 & 1.73 & 100 & \\
\hline 307.90 & 285.65 & & & & 1.00 & 297.25 & 1.94 & 100 & \\
\hline 401.70 & 284.25 & & & & 1.00 & 307.55 & 2.35 & 100 & \\
\hline 1.00 & 298.55 & 4.78 & 0 & \multirow{6}{*}{$-\overline{-} .88$} & 1.00 & 317.95 & 2.99 & 100 & \\
\hline 2.46 & 313.43 & \multirow{5}{*}{12.23} & \multirow[t]{5}{*}{0} & & 1.00 & 331.45 & 3.98 & 100 & \\
\hline 16.37 & 313.23 & & & & 1.00 & 354.65 & 7.07 & 100 & \\
\hline 25.94 & 313.02 & & & & 1.00 & 288.35 & 98.24 & 100 & \\
\hline 35.46 & 312.85 & & & & 1.00 & 294.85 & 97.87 & 100 & \\
\hline 42.99 & 312.67 & & & & 1.00 & 298.75 & 97.51 & 100 & \\
\hline 2.08 & 322.58 & 26.59 & 0 & -1.84 & 1.00 & 305.05 & 97.06 & 100 & \\
\hline 12.69 & 322.41 & & & & 1.00 & 316.15 & 96.24 & 100 & \\
\hline 24.95 & 322.18 & & & & 1.00 & 360.35 & 90.78 & 100 & \\
\hline 31.60 & 322.09 & & & & 2.61 & 310.59 & 96.27 & 100 & 0.50 \\
\hline 38.31 & 321.92 & & & & 5.02 & 310.60 & & & \\
\hline 48.90 & 321.72 & & & & 11.49 & 310.62 & & & \\
\hline 2.18 & 323.80 & 30.38 & 0 & -1.88 & 28.29 & 310.70 & & & \\
\hline 12.72 & 323.63 & & & & 35.92 & 310.76 & & & \\
\hline 25.02 & 323.40 & & & & 41.90 & 310.78 & & & \\
\hline 37.52 & 323.15 & & & & 1.00 & 323.65 & 94.49 & 100 & \\
\hline 48.44 & 322.94 & & & & & [bmi & $\left.\mathrm{PF}_{6}\right]+\mathrm{e}$ & ol + wate & \\
\hline 2.06 & 325.20 & 36.13 & 0 & -1.86 & 1.00 & 324.15 & 43.57 & 1.06 & \\
\hline 9.36 & 325.03 & & & & 1.00 & 322.95 & 43.38 & 1.82 & \\
\hline 15.49 & 324.98 & & & & 1.00 & 321.65 & 43.27 & 2.24 & \\
\hline 25.84 & 324.77 & & & & 1.00 & 320.15 & 43.14 & 2.76 & \\
\hline 34.79 & 324.59 & & & & 1.00 & 317.85 & 42.88 & 3.79 & \\
\hline 49.29 & 324.31 & & & & 1.00 & 314.65 & 42.61 & 4.84 & \\
\hline 2.18 & 325.10 & 43.24 & 0 & -2.00 & 1.00 & 311.45 & 42.32 & 5.98 & \\
\hline 12.57 & 324.88 & & & & 1.00 & 305.95 & 41.57 & 8.84 & \\
\hline 25.18 & 324.62 & & & & 1.00 & 296.55 & 40.77 & 11.79 & \\
\hline 37.43 & 324.40 & & & & 1.00 & 293.05 & 39.90 & 14.64 & \\
\hline 47.75 & 324.18 & & & & 1.00 & 289.15 & 38.45 & 19.67 & \\
\hline 1.00 & 325.18 & 43.83 & 0 & & 1.00 & 288.35 & 37.08 & 24.22 & \\
\hline 1.96 & 325.33 & 48.96 & 0 & -1.84 & 1.00 & 289.65 & 35.22 & 30.11 & \\
\hline 13.88 & 325.18 & & & & 1.00 & 294.05 & 32.55 & 37.96 & \\
\hline 24.95 & 324.96 & & & & 1.00 & 301.45 & 29.02 & 47.61 & \\
\hline 37.82 & 324.70 & & & & 1.00 & 302.65 & 28.54 & 48.81 & \\
\hline 48.02 & 324.50 & & & & 1.00 & 306.45 & 27.05 & 52.50 & \\
\hline 2.06 & 321.48 & 59.77 & 0 & -1.59 & 1.00 & 310.05 & 25.39 & 56.40 & \\
\hline 12.90 & 321.32 & & & & 1.00 & 317.35 & 22.08 & 63.69 & \\
\hline 19.79 & 321.25 & & & & 1.00 & 292.75 & 82.78 & 4.63 & \\
\hline 40.66 & 320.90 & & & & 1.00 & 288.35 & 81.96 & 9.86 & \\
\hline 48.66 & 320.74 & & & & 1.00 & 286.05 & 81.53 & 12.47 & \\
\hline 2.14 & 312.83 & 72.21 & 0 & -1.22 & 1.00 & 284.25 & 81.04 & 15.24 & \\
\hline 13.91 & 312.79 & & & & 1.00 & 283.25 & 80.59 & 17.63 & \\
\hline 24.88 & 312.61 & & & & 1.00 & 283.35 & 80.22 & 19.59 & \\
\hline 37.95 & 312.43 & & & & 1.00 & 284.05 & 79.76 & 21.83 & \\
\hline 46.77 & 312.32 & & & & 1.00 & 285.05 & 79.28 & 24.09 & \\
\hline 1.00 & 296.55 & 83.45 & 0 & & 1.00 & 287.65 & 78.56 & 27.32 & \\
\hline 1.00 & 294.55 & 84.0 & 0 & & 1.00 & 293.15 & 77.35 & 32.28 & \\
\hline & & $\mathrm{im}]\left[\mathrm{PF}_{6}\right]$ & ethanol(- $d$ & & 1.00 & 314.95 & 93.66 & 86.13 & \\
\hline 2.03 & 323.76 & 31.08 & 0 & & 1.00 & 307.05 & 91.50 & 62.73 & \\
\hline 1.81 & 324.40 & 38.28 & 0 & & 1.00 & 303.45 & 90.19 & 53.59 & \\
\hline 1.95 & 323.60 & 42.64 & 0 & & 1.00 & 289.05 & 84.50 & 31.79 & \\
\hline 1.20 & 324.13 & 45.90 & 0 & & 1.00 & 285.15 & 82.31 & 27.12 & \\
\hline 2.06 & 324.22 & 48.59 & 0 & -2.19 & 1.00 & 285.85 & 76.86 & 19.37 & \\
\hline 10.25 & 324.05 & & & & 1.00 & 286.75 & 76.01 & 18.47 & \\
\hline 19.03 & 323.86 & & & & 1.00 & 289.65 & 73.10 & 15.85 & \\
\hline 31.24 & 323.55 & & & & 1.00 & 292.75 & 70.54 & 13.96 & \\
\hline 43.94 & 323.32 & & & & 1.00 & 295.45 & 67.82 & 12.29 & \\
\hline 2.06 & 324.02 & 49.85 & 0 & -2.04 & 1.00 & 300.15 & 63.20 & 10.01 & \\
\hline 9.94 & 323.91 & & & & 1.00 & 304.45 & 58.33 & 8.16 & \\
\hline 19.86 & 323.80 & & & & 1.00 & 307.95 & 53.36 & 6.67 & \\
\hline 29.64 & 323.54 & & & & 2.04 & 288.38 & 37.15 & 24.19 & -0.05 \\
\hline 42.57 & 323.19 & & & & 20.71 & 288.37 & & & \\
\hline & & & & & 31.05 & 288.37 & & & \\
\hline & & & & & 42.76 & 288.36 & & & \\
\hline & & & & & 1.90 & 288.47 & 37.90 & 24.51 & \\
\hline & & & & & 45.70 & 288.46 & & & \\
\hline & & & & & 158.70 & 288.50 & & & \\
\hline & & & & & 244.40 & 288.53 & & & \\
\hline
\end{tabular}

\footnotetext{
${ }^{a} w_{\mathrm{IL}}$ represents the mass fraction of RTIL, with respect to the entire solution; $w_{\mathrm{H}_{2} \mathrm{O}}$ represents the mass fraction of water in the mixed solvent.
} 


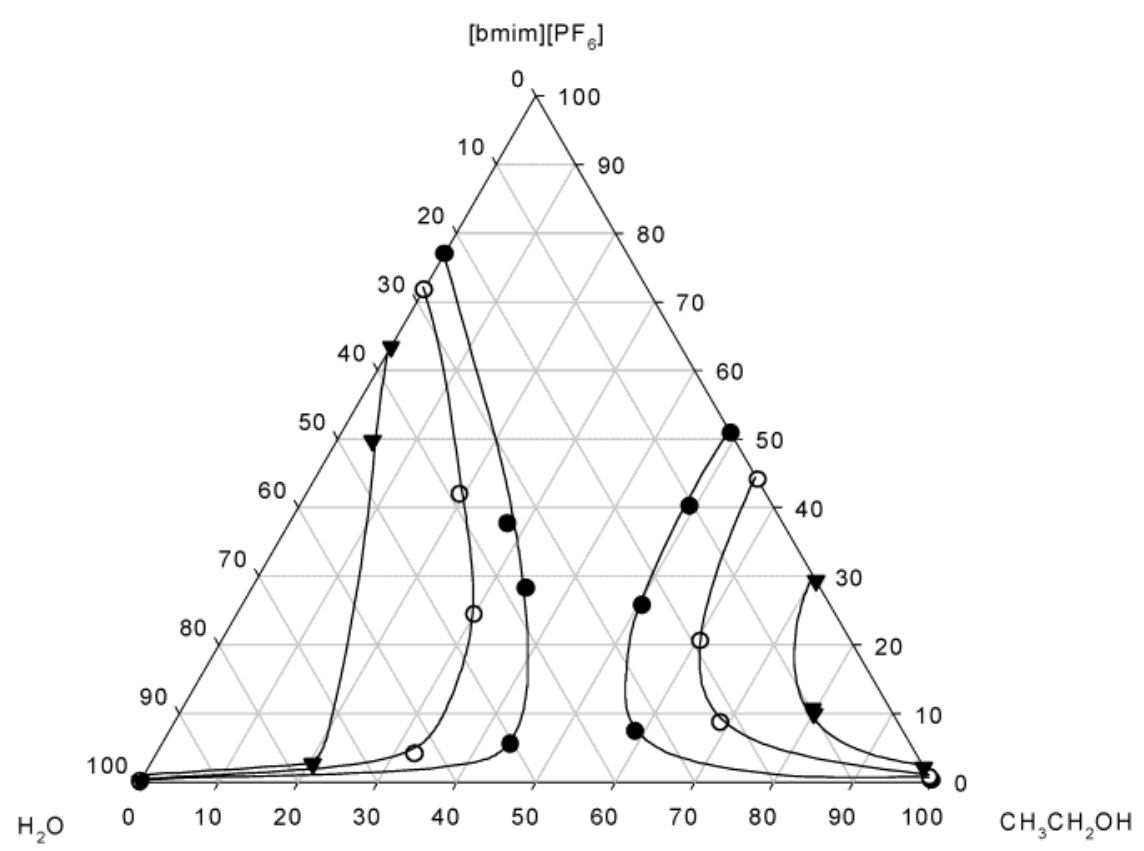

Figure 3. Ternary phase diagram of the $[\mathrm{bmim}]\left[\mathrm{PF}_{6}\right]+$ water + ethanol system, in mole percentage, at three temperatures: $(\bullet) 290.15 \mathrm{~K}(\mathrm{O})$ $298.15 \mathrm{~K}$, and $(\boldsymbol{\nabla}) 313.15 \mathrm{~K}$.

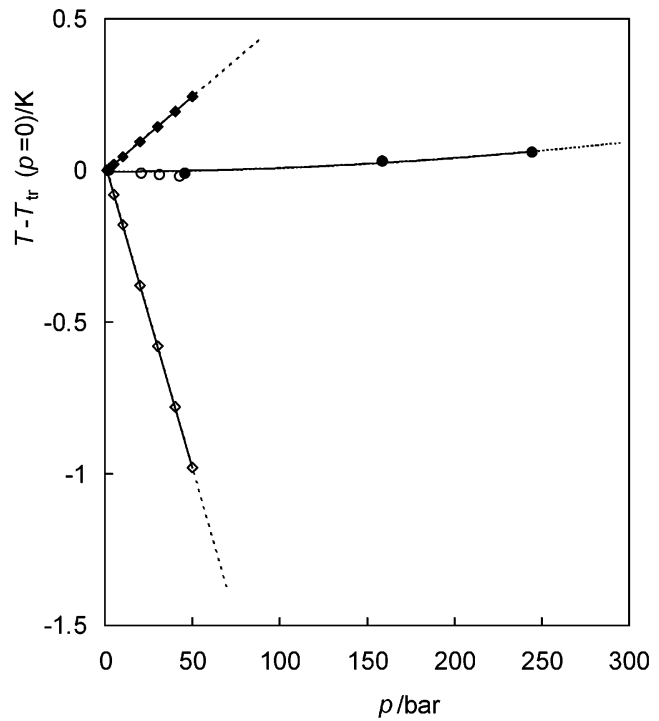

Figure 4. Pressure effects in the liquid-liquid equilibria of binary and ternary mixtures of $[\mathrm{bmim}]\left[\mathrm{PF}_{6}\right]+$ water + ethanol: $(\diamond)[\mathrm{bmim}]-$ $\left[\mathrm{PF}_{6}\right]+$ ethanol, $(\diamond)[\mathrm{bmim}]\left[\mathrm{PF}_{6}\right]+$ water, and $(\mathrm{O}, \bullet)[\mathrm{bmim}]\left[\mathrm{PF}_{6}\right]$ +0.5 water +0.5 ethanol (open circles refer to data obtained in the low-pressure cell, whereas the filled circles were obtained in the highpressure cell). Effects are represented as differences between the transition temperature at a given pressure $(T)$ and that at a null nominal pressure.

neither pressure nor isotope effects have ever been reported for the liquid-liquid equilibrium of RTILs. Swatloski et al. ${ }^{13}$ studied the 1-alkyl-3-methylimidazolium (alkyl = butyl, hexyl, or octyl) hexafluorophosphate + water + ethanol ternary systems at atmospheric pressure and at a single temperature of $298.15 \mathrm{~K}$. These authors have shown that increases in the length of the alkyl chain in the IL leads to improved mutual solubility between the RTIL and ethanol but worsens that of water in the ionic liquid. Solubility data of $[\mathrm{bmim}]\left[\mathrm{PF}_{6}\right]+$ water were also presented by Anthony et al. ${ }^{14}$ at three temperatures. The results of Swatloski et al. seem to consistently underestimate the solubility of water and that of ethanol in the $[\mathrm{bmim}]\left[\mathrm{PF}_{6}\right]$, judging from comparisons with the current work (and ref 3)

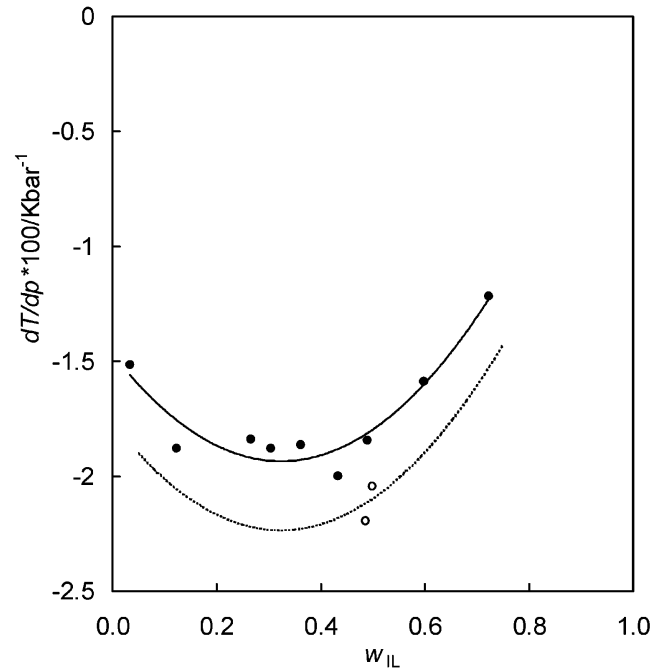

Figure 5. Pressure derivative of the temperature of transition of [bmim]$\left[\mathrm{PF}_{6}\right]+$ ethanol versus the concentration of RTIL, expressed as a mass fraction. Filled circles and the solid curve represent normal ethanol as the solvent, whereas open circles and the dotted line represent data for $d_{1}$-ethanol. Lines are drawn as guides to the data.

and ref 14 for water, and the current work (and ref 3) for ethanol. In respect to the solubility of water in $[\mathrm{bmim}]\left[\mathrm{PF}_{6}\right]$ at 298.15 $\mathrm{K}$, we have found, in accordance with Anthony et al., a mole fraction value of 0.28 , whereas the value reported by Swatloski et al. is only 0.16 . When ethanol has been used as a solvent, we have found a mole fraction of 0.57 , compared to a value of 0.41 (taken from ref 13 ), for its solubility in $\left[\mathrm{bmim}^{2}\left[\mathrm{PF}_{6}\right]\right.$ at $298.15 \mathrm{~K}$. The discrepancy may be due to short contact and a failure to reach equilibrium in the case of the latter work. During the initial stages of writing the present article, we became aware of the works of Marsh et al. ${ }^{15,16}$ on the atmospheric pressure binary phase diagrams of $[\mathrm{bmim}]\left[\mathrm{PF}_{6}\right]+$ ethanol, + propanol, + butanol, and those of $\left[\mathrm{R}_{n} \mathrm{mim}\right]\left[\mathrm{PF}_{6}\right](n=4,5,6,7,8)+$ 1-butanol. This group has shown that alcohols with longer alkyl chains have lower solvent quality for the dissolution of [bmim]$\left[\mathrm{PF}_{6}\right]$, and that longer alkyl substitutions on the RTIL cation induce better solubility in 1-butanol. The comparison of their 
TABLE 2: Cloud-Point Data and Their Pressure Dependence for $[\mathrm{bmim}]\left[\mathrm{NTf}_{2}\right]+2$-Methylpropanol + Water $^{a}$

\begin{tabular}{|c|c|c|c|c|}
\hline$p$ (bar) & $T(\mathrm{~K})$ & $10^{2} w_{\mathrm{IL}}$ & $10^{2} w_{\mathrm{H}_{2} \mathrm{O}}$ & $10^{2} \mathrm{~d} T / \mathrm{d} p(\mathrm{~K} / \mathrm{bar})$ \\
\hline \multicolumn{5}{|c|}{$[$ bmim $]\left[\mathrm{NTf}_{2}\right]+2$-Methylpropanol } \\
\hline 1.00 & 285.02 & 5.29 & 0 & \\
\hline 2.47 & 297.96 & 14.43 & 0 & -0.33 \\
\hline 9.20 & 297.93 & & & \\
\hline 21.81 & 297.89 & & & \\
\hline 30.06 & 297.86 & & & \\
\hline 41.33 & 297.83 & & & \\
\hline 2.41 & 301.36 & 21.14 & 0 & -0.24 \\
\hline 9.73 & 301.35 & & & \\
\hline 21.10 & 301.32 & & & \\
\hline 31.85 & 301.29 & & & \\
\hline 41.60 & 301.27 & & & \\
\hline 2.23 & 303.51 & 30.67 & 0 & 0.08 \\
\hline 6.86 & 303.57 & & & \\
\hline 10.02 & 303.56 & & & \\
\hline 20.89 & 303.54 & & & \\
\hline 30.62 & 303.55 & & & \\
\hline 43.84 & 303.58 & & & \\
\hline 2.06 & 303.68 & 33.77 & 0 & -0.40 \\
\hline 9.51 & 303.63 & & & \\
\hline 20.10 & 303.60 & & & \\
\hline 29.84 & 303.56 & & & \\
\hline 43.34 & 303.51 & & & \\
\hline 2.89 & 303.35 & 50.86 & 0 & -0.26 \\
\hline 12.65 & 303.34 & & & \\
\hline 21.73 & 303.30 & & & \\
\hline 30.97 & 303.27 & & & \\
\hline 43.57 & 303.25 & & & \\
\hline 2.10 & 302.33 & 58.71 & 0 & -0.12 \\
\hline 21.00 & 302.31 & & & \\
\hline 31.87 & 302.30 & & & \\
\hline 44.24 & 302.28 & & & \\
\hline 2.14 & 293.05 & 75.26 & 0 & -0.18 \\
\hline 21.13 & 293.01 & & & \\
\hline 42.33 & 292.98 & & & \\
\hline 29.26 & 292.99 & & & \\
\hline 1.00 & 292.45 & 8.58 & 0 & - \\
\hline 1.00 & 303.55 & 41.96 & 0 & - \\
\hline 1.00 & 303.55 & 48.97 & 0 & \\
\hline 1.00 & 303.55 & 50.38 & 0 & \\
\hline 1.00 & 300.65 & 64.86 & 0 & \\
\hline 1.00 & 284.95 & 81.15 & 0 & \\
\hline \multicolumn{5}{|c|}{$[\mathrm{bmim}]\left[\mathrm{NTf}_{2}\right]+2-$ Methylpropanol + water } \\
\hline 1.00 & 292.95 & 49.79 & 2.31 & \\
\hline 1.00 & 280.45 & 49.18 & 4.66 & \\
\hline 1.00 & 270.65 & 48.73 & 6.38 & \\
\hline 1.00 & 264.15 & 48.19 & 8.36 & \\
\hline 1.00 & 260.15 & 47.66 & 10.31 & \\
\hline 1.00 & 258.15 & 47.11 & 12.27 & \\
\hline 1.00 & 258.15 & 46.23 & 15.30 & \\
\hline 1.00 & 271.15 & 45.66 & 17.24 & \\
\hline 1.00 & 290.95 & 45.13 & 18.98 & \\
\hline 1.00 & 303.85 & 44.54 & 20.89 & \\
\hline 1.00 & 307.15 & 43.96 & 22.71 & \\
\hline 1.00 & 263.15 & 45.62 & 16.92 & \\
\hline 1.00 & 287.15 & 44.70 & 19.94 & \\
\hline 1.00 & 283.25 & 50.01 & 3.90 & \\
\hline 1.00 & 262.15 & 48.47 & 9.64 & \\
\hline 1.00 & 257.15 & 47.14 & 14.32 & \\
\hline 1.00 & 266.15 & 46.26 & 17.30 & \\
\hline
\end{tabular}

${ }^{a} w_{\mathrm{IL}}$ represents the mass fraction of RTIL, with respect to the entire solution; $w_{\mathrm{H}_{2} \mathrm{O}}$ represents the mass fraction of water in the mixed solvent.

results with ours (for ethanol) shows an impressive degree of accord, because both data are totally indistinguishable within the overall uncertainty of $\pm 0.5 \mathrm{~K}$, or \pm 0.01 in IL mass fraction, in the entire concentration range.

Heintz et al. ${ }^{17}$ very recently reported on the determination of phase diagrams for 1-ethyl-3-methylimidazolium bis(trifluo-
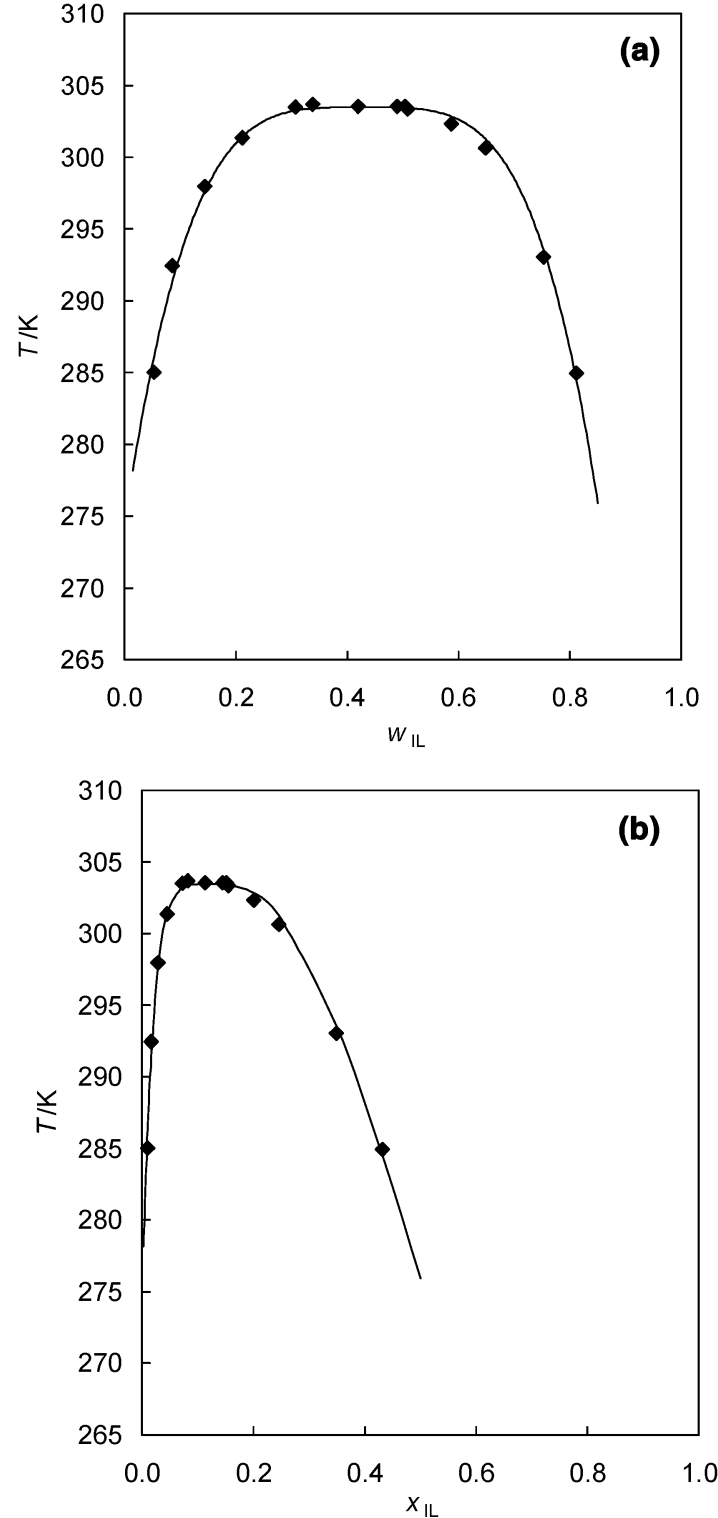

Figure 6. Atmospheric-pressure phase diagram of binary liquid [bmim]$\left[\mathrm{NTf}_{2}\right]+2$-methylpropanol mixtures using two different field variables: (a) mass fraction $\left(w_{\mathrm{IL}}\right)$ and (b) mole $\left(x_{\mathrm{IL}}\right)$ fraction of [bmim] $\left[\mathrm{PF}_{6}\right]$. Solid lines represent least-squares fits to experimental data (denoted by solid diamond symbols), using the scaling-type eq 1 . Parameters are reported in Table 3. The two-phase region is located inside the envelope defined by the line.

romethylsulfonyl)imide, [emim] $\left[\mathrm{NTf}_{2}\right],+$ propanol, + butanol, and + pentanol. The miscibility worsens as one moves upward in the alcohols' family. A direct comparison is not possible, because their alkyl substitution at the 1-position of the imidazolium ring is different (ethyl instead of butyl), as are the alcohols (butanol and propanol versus 2-methylpropanol). In any case, our phase diagram lies well between theirs for propanol and butanol.

3.3. Phenomenological Model and the Prigogine-Defay Equation. Despite the limited experimental information available on accurate phase diagrams of mixtures of RTIL + conventional solvents,, $313-17$ it is commonly observed that the $T, x$ projection of the binary phase diagram is extremely skewed toward low mole fractions of RTIL (also see Figures $1 \mathrm{~b}$ and $6 b)$. Typically, molar volumes of RTILs are much greater than those of low-molecular-mass conventional solvents. This also is a situation normally encountered in polymer-solvent solu- 


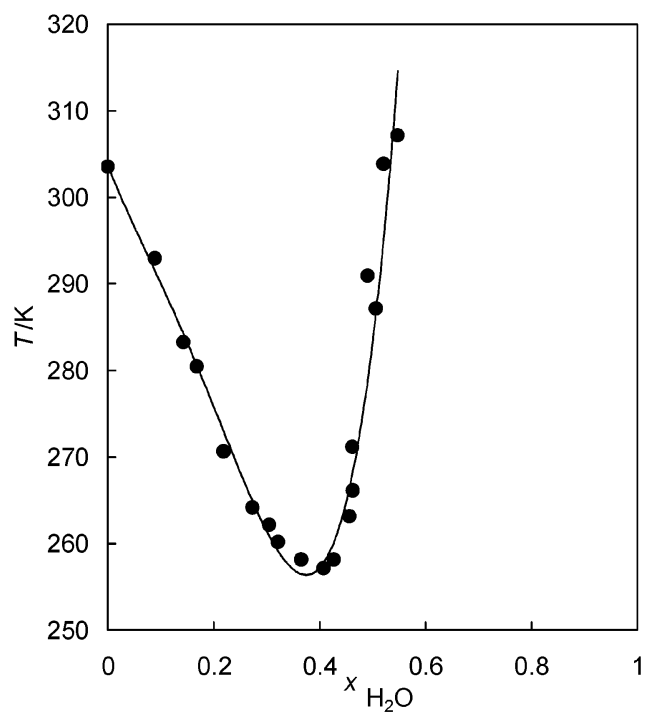

Figure 7. Effect of the addition of water on the near-critical temperature of transition of the liquid $[\mathrm{bmim}]\left[\mathrm{NTf}_{2}\right]+\left[x \mathrm{H}_{2} \mathrm{O}+(1-\right.$ $x$ )2-methylpropanol]; $x$ represents the mole fraction of water in the mixed solvent. Lines are drawn as guides to the data.

TABLE 3: Parameters of the Scaling-Type Equation (eq 1) for a Nominal Pressure of 1 bar

\begin{tabular}{lcc}
\hline & {$[$ bmim $]\left[\mathrm{PF}_{6}\right]+$ ethanol } & {$[$ bmim $]\left[\mathrm{NTf}_{2}\right]+2$-methylpropanol } \\
\hline$A$ & 0.789 & 1.010 \\
$\beta$ & 0.295 & 0.257 \\
$T_{\mathrm{c}}(\mathrm{K})$ & 324.8 & 303.5 \\
$w_{\mathrm{c}}$ & 0.42 & 0.43
\end{tabular}

tions. The asymmetry in the phase diagram is due to a mixing entropic effect that originates from the large difference between the volumes occupied by the mixture's components. In a lattice model, the entire volume is divided into segments that are approximately the size of the low-molecular-volume constituent. The high-molar-volume component may occupy several of these segments. Hetero interactions between unlike molecules are referenced to adjacent segments occupied by one molecule of solvent and (part of) the high-molecular-mass component. Although this type of model is typically applied to systems where the components differ significantly in size (e.g., polymer solutions), both Schneider $^{18}$ and our group ${ }^{19}$ have already successfully used similar models to interpret other types of systems, such as those where the components are both small and relatively similar in size (e.g., water + methylpyridine).

The current model is inspired on the aforementioned lattice models (such as the Flory-Huggins model) and one of its possible modifications. ${ }^{5 b}$ It becomes more versatile both by allowance for a compressible lattice (the parameters are generally dependent on pressure) and by a more complicated temperature dependence of the enthalpic term. ${ }^{5 a, 10}$ In this "polymer-like" approach, the simplest binary $G^{\mathrm{E}}$-model that emerges corresponds to a molar Gibbs energy change upon mixing, which is expressed by the relation ${ }^{18,19}$

$$
\Delta G_{\mathrm{m}}(\mathrm{J} / \mathrm{mol})=R T\left(x_{1} \ln \varphi_{1}+x_{2} \ln \varphi_{2}+\chi(T) x_{2} \varphi_{1}\right)
$$

where the subscripts 1 and 2 refer to the larger and smaller components, respectively; $x_{i}$ denotes the mole fraction of component $i, \varphi_{i}$ is the segment fraction of component $i$, and $\chi(T)$ is the segment-segment temperature-dependent interaction parameter between unlike molecules, which is a measure of the excess Gibbs energy of the mixture (the last term of eq 2). Segment fractions are easily related to mole frac- tions, using eqs 3 and 4 :

$$
\begin{aligned}
\varphi_{1} & =\frac{r x_{1}}{r x_{1}+x_{2}} \\
\varphi_{2} & =\frac{x_{2}}{r x_{1}+x_{2}}
\end{aligned}
$$

where $r$ is the number of segments occupied by component 1 . To produce a realistic model, $r$ should not differ greatly from the ratio of molar volumes of the pure components $\left(r \approx V_{1} /\right.$ $V_{2}$ ). If one wishes to express the Gibbs energy change in the segment - mole space, $\Delta G_{\mathrm{m}}^{*}$, the following expression applies:

$$
\frac{\Delta G_{\mathrm{m}}}{r x_{1}+x_{2}}=\Delta G_{\mathrm{m}}^{*}=R T\left(\frac{\varphi_{1}}{r} \ln \varphi_{1}+\varphi_{2} \ln \varphi_{2}+\chi(T) \varphi_{1} \varphi_{2}\right)
$$

Note that, although in this segment-mole space, the excess Gibbs energy is symmetrically centered around the equimolar composition (the last term of eq 5), in the mole space, it is slightly asymmetrical, in respect to composition:

$$
\Delta G^{\mathrm{E}}(\mathrm{J} / \mathrm{mol})=R T\left[\left(r x_{1}+x_{2}\right) \chi(T) \varphi_{1} \varphi_{2}\right]=R T \chi(T) \frac{r x_{1} x_{2}}{r x_{1}+x_{2}}
$$

From this point forward, many other thermodynamic properties can be derived, using well-known relations. For instance, the excess molar enthalpy of mixing is given by

$$
\Delta H^{\mathrm{E}}(\mathrm{J} / \mathrm{mol})=R T\left[\left(r x_{1}+x_{2}\right) \chi^{\prime}(T) \varphi_{1} \varphi_{2}\right]=R T \chi^{\prime}(T) \frac{r x_{1} x_{2}}{r x_{1}+x_{2}}
$$

where

$$
\chi^{\prime}(T)=-T \frac{\mathrm{d} \chi}{\mathrm{d} T}
$$

The simplest $G^{\mathrm{E}}$-model capable of generating all types of basic liquid-liquid equilibria ${ }^{5}$ is one in which the interaction parameter depends on temperature, as

$$
\chi(T)=d_{0}+\frac{d_{1}}{T}-d_{2} \ln T
$$

and where $d_{0}$ and $d_{1}$ are generally pressure-dependent., ${ }^{5,10}$ In this case, at a given pressure,

$$
\chi^{\prime}(T)=\frac{d_{1}}{T}+d_{2}
$$

In turn, the difference between the molar chemical potential of component $i$ in solution and in its pure state is given by eqs 11 and 12, respectively:

$$
\begin{aligned}
& \frac{\Delta \mu_{1}}{R T}=\ln \varphi_{1}+(1-r)\left(1-\varphi_{1}\right)+r \chi\left(1-\varphi_{1}\right)^{2} \\
& \frac{\Delta \mu_{2}}{R T}=\ln \varphi_{2}+\left(1-\frac{1}{r}\right)\left(1-\varphi_{2}\right)+\chi\left(1-\varphi_{2}\right)^{2}
\end{aligned}
$$

If one wishes to express the same quantities in the segmentmole space, eq 11 must be divided by $r$, whereas eq 12 remains the same. In this case, segment-molar activity coefficients, 
$\gamma_{i}^{*}$, are defined by the following equations:

$$
\begin{gathered}
\frac{\mu_{1}^{*}}{R T}=\frac{\mu_{1}^{*, 0}}{R T}+\left(\frac{1}{r}\right) \ln \varphi_{1}+\left(\frac{1-r}{r}\right) \varphi_{2}+\ln \gamma_{1}^{*} \\
\frac{\mu_{2}^{*}}{R T}=\frac{\mu_{2}^{*, 0}}{R T}+\ln \varphi_{2}+\left(1-\frac{1}{r}\right) \varphi_{1}+\ln \gamma_{2}^{*}
\end{gathered}
$$

Therefore,

$$
\begin{gathered}
\ln \gamma_{1}^{*}=\chi \varphi_{2}^{2} \\
\ln \gamma_{2}^{*}=\chi \varphi_{1}^{2} \\
\ln \gamma_{1}^{*, \infty}=\ln \gamma_{2}^{*, \infty}=\chi
\end{gathered}
$$

This method of separating the ideal from the nonideal components of the mixing process is conventionally based on the developments of lattice theories ${ }^{20}$ (or cell models, such as the TIE; ${ }^{6}$ see below). In turn, one may want to express nonideality, as is traditionally done in classical thermodynamics, stating that the molar Gibbs energy of mixing, $\Delta G_{\mathrm{m}}=x_{1} \Delta \mu_{1}$ $+x_{2} \Delta \mu_{2}$ (see eqs 2,11 , and 12 ), is given by

$$
\frac{\Delta G_{\mathrm{m}}}{R T}=x_{1} \ln \left(x_{1} \gamma_{1}\right)+x_{2} \ln \left(x_{2} \gamma_{2}\right)
$$

Under this formulation, activities of a given component $i\left(a_{i}\right)$ in a mixture are given by the exponential of eqs 11 or 12 . Activity coefficients, $\gamma_{i}=a_{i} / x_{i}$, depend on the chosen reference standard state. Here, $\gamma_{i}=1$ when $x_{i}=1$. Therefore, from eqs 11 and 12 , one obtains

$$
\begin{gathered}
\ln \gamma_{1}=\ln r-\ln \left(r x_{1}+x_{2}\right)+(1-r) \varphi_{2}+r \chi \varphi_{2}^{2} \\
\ln \gamma_{2}=-\ln \left(r x_{1}+x_{2}\right)+\left(1-\frac{1}{r}\right) \varphi_{1}+\chi \varphi_{1}^{2}
\end{gathered}
$$

and, at infinite dilution,

$$
\begin{aligned}
& \ln \left(\gamma_{1}^{\infty}\right)=\ln r+(1-r)+r \chi \\
& \ln \left(\gamma_{2}^{\infty}\right)=-\ln r+\left(1-\frac{1}{r}\right)+\chi
\end{aligned}
$$

For the case of similar-sized systems ( $r=1)$, eqs $2-7,11$, and 12 recover their more commonly recognized forms, and, in particular, $\chi=\ln \left(\gamma_{1}^{\infty}\right)=\ln \left(\gamma_{2}^{\infty}\right)$.

The use of the usual criterion of stability ${ }^{5}$ for a single-phase binary system (the second derivative of the Gibbs energy, with respect to composition, is equal to zero), coupled with that which is specific to the binary critical point (the third derivative), lead to constraints that both the interaction parameter and the composition must meet at the critical point, namely,

$$
\begin{gathered}
x_{1, \mathrm{c}}=\frac{1}{1+r^{3 / 2}} \\
\varphi_{1, c}=\frac{1}{1+r^{1 / 2}} \\
\chi_{\mathrm{c}}=\frac{1}{2}\left(1+\frac{1}{r^{1 / 2}}\right)^{2}
\end{gathered}
$$

Again, note that, when we reduce the model to $r=1$, the critical value for the interaction parameter is 2 and the critical mole fraction is 0.5 .

At a given pressure, the system phase-separates whenever $\chi(T)$ reaches a critical value that is dictated by eq 22 . Consequently, the system phase-separates if the activity coefficients of the mixture's components (expressed at infinite dilution) are equal to or greater than the values imposed by the following relations. For segment-molar activity coefficients, one finds

$$
\ln \left(\gamma_{1}^{*, \infty}\right)=\ln \left(\gamma_{2}^{*, \infty}\right) \geq \frac{1}{2}\left(1+\frac{1}{r^{1 / 2}}\right)^{2}
$$

and, for the molar activity coefficients,

$$
\begin{aligned}
& \ln \left(\gamma_{1}^{\infty}\right) \geq \ln r+(1-r)+r\left(\frac{1}{2}\right)\left(1+\frac{1}{r^{1 / 2}}\right)^{2} \\
& \ln \left(\gamma_{2}^{\infty}\right) \geq-\ln r+\left(1-\frac{1}{r}\right)+\frac{1}{2}\left(1+\frac{1}{r^{1 / 2}}\right)^{2}
\end{aligned}
$$

The two binary systems studied herein and involving an alcohol as one of the components phase-separate by either decreasing the temperature at constant pressure (the upper critical solution temperature, UCST) or decreasing the pressure at constant temperature (the upper critical solution pressure, UCSP). They belong to the class (UCST, UCSP). This situation can only occur if the $T-p$ critical line has a negative slope. The $T-p$ slope of the critical line is related to the second derivatives, with respect to the composition of the excess enthalpy and excess volume (for a detailed analysis of this relationship, see, for instance, refs 5, 18, 21, and references therein). Under some assumptions (in practice, the two excess properties must have a similar form, with respect to composition, and present no inflection points), one obtains a Clapeyron-type of relation, which can be expressed as

$$
\left(\frac{\mathrm{d} T}{\mathrm{~d} p}\right)_{\mathrm{c}} \cong T_{\mathrm{c}}(p) \frac{\Delta V^{\mathrm{E}}\left(T_{\mathrm{c}}(p), x\right)}{\Delta H^{\mathrm{E}}\left(T_{\mathrm{c}}(p), x\right)}
$$

The current compressible lattice model, which conforms inherently to the aforementioned constraints, produces eq 26 as a true equality. This is thoroughly demonstrated in ref 5 .

Within the aforementioned constraints, a system that phaseseparates on cooling must present a positive excess enthalpy. ${ }^{5,21}$ Therefore, because the $T-p$ slopes are negative, one can anticipate that both $[\mathrm{bmim}]\left[\mathrm{PF}_{6}\right]+$ ethanol and $[\mathrm{bmim}]\left[\mathrm{NTf}_{2}\right]$ +2 -methylpropanol are expected to have $\Delta V^{\mathrm{E}}<0$ and $\Delta H^{\mathrm{E}}>$ 0 .

We have used the current model (in a simplified version, where the interaction parameter defined by eq 9 was set to $d_{2}$ $=0$ ) to find the best values of $d_{0}$ and $d_{1}$ that would reproduce the experimental phase diagrams. This is done by an algorithm written in Mathematica that simultaneously equates the chemical potential (eqs 13 and 14) of each component in both phases. Values of $r$ (4.6 and 4.2, respectively) were fixed to approximately generate the right critical compositions (see eq 21 and Table 3). Figures 8 and 9 depict the good agreement between modeled and experimental results for $[\mathrm{bmim}]\left[\mathrm{PF}_{6}\right]+$ ethanol and [bmim] $\left[\mathrm{NTf}_{2}\right]+2$-methylpropanol, respectively. The $r$-values are effective values. They are slightly higher than the average ratio of molar volumes of the pure components in the temperature range of $298-323 \mathrm{~K}$, which amount to 3.5 and 3.1 , respectively, for each system. From the fitted parameters, one first obtains a prediction of the excess enthalpy (eq 7) at 


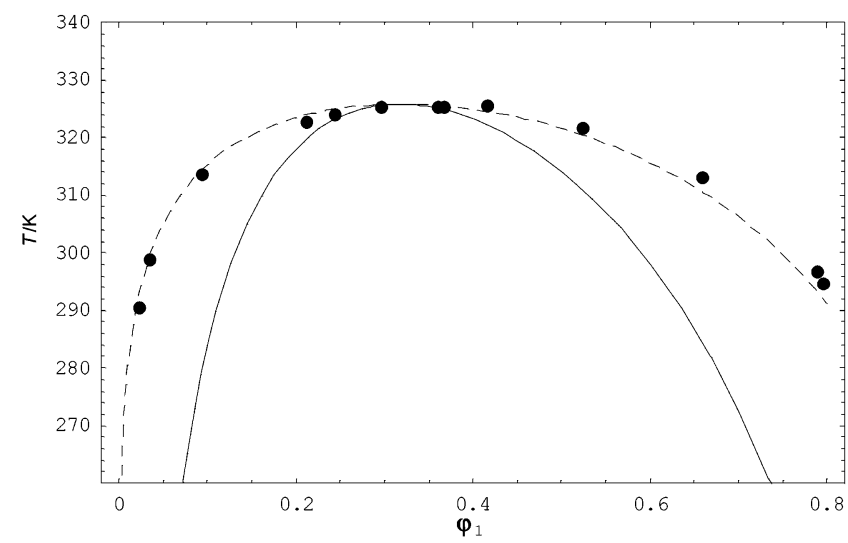

Figure 8. Experimental and modeled phase diagrams of $[\mathrm{bmim}]\left[\mathrm{PF}_{6}\right]$ + ethanol compared in a plot of temperature versus segment fraction of RTIL $\left(\varphi_{1}\right)$ (see Table 4, $r($ II $)=4.6$ ). Filled circles represent experimental data. Dashed and solid lines represent modeled binodal and spinodal curves, respectively.

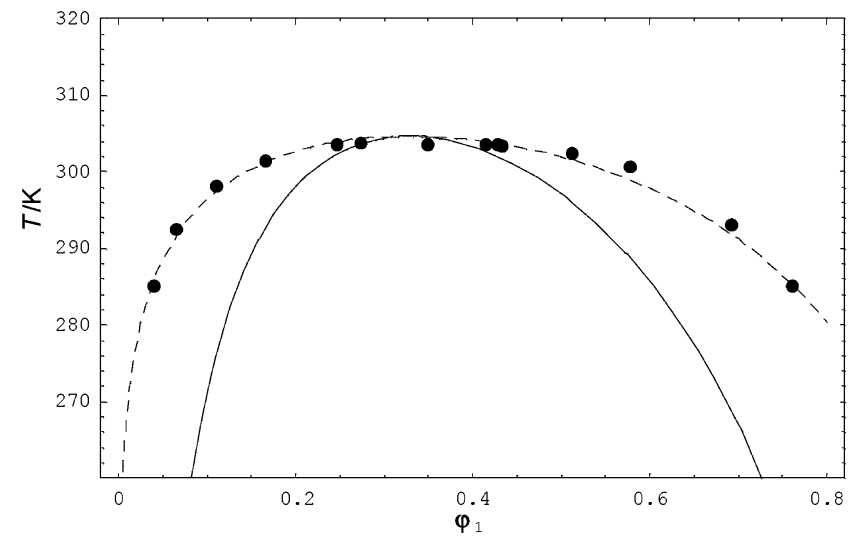

Figure 9. Experimental and modeled phase diagrams of [bmim] $\left[\mathrm{NTf}_{2}\right]$ + 2-methylpropanol compared in a plot of temperature versus segment fraction of RTIL $\left(\varphi_{1}\right)$ (see Table 4, $r(\mathrm{II})=4.2$ ). Filled circles represent experimental data. Dashed and solid lines hold for modeled binodal and spinodal curves, respectively.

the critical temperature and, then, using the Prigogine-Defay expression (eq 26), an estimation of the excess volume. The results are reported in Table 4 . In both cases, although the phase diagrams are extremely skewed to the low-mole-fraction side in RTIL $\left(x_{\mathrm{IL}, \mathrm{c}} \approx 0.1\right)$, the shape of the excess properties versus the mole fraction of RTIL is predicted to be much more symmetrical, with their extreme value being reached for a value of $x_{\mathrm{IL} \text {,ext }} \approx 0.34$. In both systems, the endothermic processes, upon mixing, are highly energetic (accompanied by significant cooling) and correspond to a contraction that is 6 times more visible in $[\mathrm{bmim}]\left[\mathrm{PF}_{6}\right]+$ ethanol than in $[\mathrm{bmim}]\left[\mathrm{NTf}_{2}\right]+$ 2-methylpropanol. These expectations should be judged by comparison with direct volumetric and enthalpic determinations. Although this comparison is not yet possible for these specific systems, the aforementioned strategy of relating the experimental phase diagram to model parameters and then to excess properties seems promising. For instance, we are currently involved in a detailed experimental and theoretical study ${ }^{22}$ of another similar system $\left([\mathrm{bmim}]\left[\mathrm{BF}_{4}\right]+\right.$ water $)$, and the preliminary results show that the model's results (at $278 \mathrm{~K}$ ) of $H_{\mathrm{max}}^{\mathrm{E}} \approx+3000 \mathrm{~J} / \mathrm{mol}$ and $V_{\max }^{\mathrm{E}} \approx+0.2 \times 10^{-6} \mathrm{~m}^{3} / \mathrm{mol}$ agree with the experimental results.

We have also tested the model in a distinct way. Very recently, Heintz et al. ${ }^{23}$ reported temperature-dependent molar activity coefficients at infinite dilution of a large number of organic solvents in $\left[\mathrm{NTf}_{2}\right]^{-}$-based ionic liquids. These are obtained by a gas chromatographic technique, using the ionic liquid as the stationary phase. In the specific case where the cation is the 1-methyl-3-ethyl-imidazolium, there are experimentally determined ${ }^{17}$ phase diagrams of this RTIL with propanol, butanol, and pentanol. Equation 25 dictates the value of the activity coefficient at infinite dilution of the smaller component (organic solvent) that defines the border between homogeneous one-phase and heterogeneous two-phase regions. Table 5 shows these calculated critical values of $\gamma^{\infty}$ for the three alcohols and compares them with those obtained at several temperatures using the chromatographic technique. This comparison establishes the prediction of occurrence of critical demixing in these systems. Although the agreement is only semiquantitative, it is highly rewarding to verify that, from the chromatographic data, one is able to predict the existence of phase separation in these systems.

The magnitude of the solvent-solute interactions can be measured by the partial molar enthalpy of component 2 at infinite dilution in component $1, H_{2}^{\mathrm{E}, \infty}=R \partial \ln \left(\gamma_{2}{ }^{\infty}\right) / \partial(1 / T)$. Heintz et al. $^{23}$ provided these values for the mixtures that involved the three alcohols. On the other hand, in the language of the currently adopted $G^{\mathrm{E}}$-model, this same quantity is given by the parameter $R d_{1}$. Table 6 compares their results with ours for systems that involve RTIL + alcohol.

3.4. Isotopic Shift, Given the Statistical-Mechanical Theory of Isotope Effects. Within the framework of the statistical-mechanical theory of isotope effects, ${ }^{6}$ the difference ( $\Delta=$ light - heavy) in the chemical potentials between two isotopomers and between two different states (here, meaning infinite dilution and pure state; $\delta=-(" \infty "-$ " $\bigcirc$ ") is directly related to the vibrational structure of the system embedded in a lattice (cell) model. Assuming that the potential energy surface is isotope-independent and that the entire set of vibrational frequencies can be separated into a low-frequency set (external motions associated with hindered translations and rotations) and a high-frequency set (internal vibrations), one obtains the approximate relation for component 2 :

$$
\begin{aligned}
\frac{\delta \Delta \mu_{2}^{*}}{R T} \approx \frac{1}{24}\left(\frac{h c}{k T}\right)^{2} \sum_{\mathrm{ext}}^{6}\left[\left(v_{i}^{\prime 2}-v_{i}^{2}\right)^{\circ}-\left(v_{i}^{\prime 2}-v_{i}^{2}\right)^{\infty}\right]+ \\
\frac{1}{2}\left(\frac{h c}{k T}\right)^{3 n-6} \sum_{\mathrm{int}}^{3 n}\left[\left(v_{i}^{\prime}-v_{i}\right)^{\circ}-\left(v_{i}^{\prime}-v_{i}\right)^{\infty}\right]
\end{aligned}
$$

where the $v_{i}$ values are the wavenumbers that characterize the $i$ th vibrational mode and the prime symbol denotes the light isotopomer.

From the phenomenological model used in this work, one concludes (eq 14) that

$$
\frac{\mu_{2}^{*}-\mu_{2}^{*, \theta}}{R T}=\chi \varphi_{1}^{2}
$$

where the superscript $\theta$ represents the ideal conditions. At infinite dilution of component 2 in component 1 and at a given pressure, then

$$
R T=\frac{\left(\mu_{2}^{*}-\mu_{2}^{*, \theta}\right)^{\infty}}{\chi(T)}
$$

where $\chi(T)$ expresses the functional dependence of the segment-segment interaction parameter (e.g., eq 9). Typically, the situation encountered when one compares two mixtures that 
TABLE 4: Parameters of the $G^{\mathrm{E}}$ Model Using Values of $r$ Taken as (I) Direct Ratios of Molar Volumes and (II) an Optimized Match with Experimental Critical Composition (See eq 21)

\begin{tabular}{|c|c|c|c|c|}
\hline & \multicolumn{2}{|c|}{$[$ bmim $]\left[\mathrm{PF}_{6}\right]+$ ethanol } & \multicolumn{2}{|c|}{$[$ bmim $]\left[\mathrm{NTf}_{2}\right]+2$-methylpropanol } \\
\hline & $r(\mathrm{I})=3.537$ & $r(\mathrm{II})=4.6$ & $r(\mathrm{I})=3.107$ & $r(\mathrm{II})=4.2$ \\
\hline$R d_{1}(\mathrm{~J} / \mathrm{mol})$ & 10931 & 10397 & 13873 & 13119 \\
\hline$R d_{0}\left(\mathrm{~J} \mathrm{~mol}^{-1} \mathrm{~K}^{-1}\right)$ & -23.77 & -22.97 & -35.19 & -33.85 \\
\hline$T_{\mathrm{c}}(\mathrm{K})$ & 326.1 & 325.9 & 305.5 & 304.7 \\
\hline$\varphi_{1, \mathrm{c}}$ & 0.347 & 0.318 & 0.362 & 0.328 \\
\hline$x_{1}^{\max _{a}}$ & 0.347 & 0.318 & 0.362 & 0.328 \\
\hline$H_{1}^{\mathrm{E}}(\mathrm{J} / \mathrm{mol})$ & +4660 & +4830 & +5650 & +5920 \\
\hline$V_{\max }^{\mathrm{E}}\left(\times 10^{6} \mathrm{~m}^{3} / \mathrm{mol}\right)$ & -2.9 & -3.0 & -0.48 & -0.50 \\
\hline
\end{tabular}

${ }^{a} x_{1}^{\max }$ represents the mole fraction of RTIL at the extremum of the excess properties.

TABLE 5: Experimental Molar Activity Coefficients at Infinite Dilution $\left(\gamma_{2}^{\infty}\right)$ of Three Alcohols in [emim][ $\left.\mathbf{N T f}_{2}\right]$ (Taken from Ref 23) and Corresponding Critical Temperatures of Phase Separation $\left(T_{c}\right)$

\begin{tabular}{|c|c|c|c|c|c|c|}
\hline & \multicolumn{4}{|c|}{$\gamma_{2}^{\infty}($ from ref 23$)$} & \multirow{2}{*}{$\begin{array}{l}T_{\mathrm{c}}, \text { from } \\
\text { ref } 17(\mathrm{~K})\end{array}$} & \multirow{2}{*}{$\begin{array}{c}\gamma_{2}^{\mathrm{S}, \infty} \\
(\text { from eq 25) }\end{array}$} \\
\hline & $313 \mathrm{~K}$ & $323 \mathrm{~K}$ & $333 \mathrm{~K}$ & $343 \mathrm{~K}$ & & \\
\hline & 2.1 & 1.9 & 1.8 & 1.6 & 294 & 2.0 \\
\hline & 3.0 & 2.7 & 2.4 & 2.2 & 321 & 2.5 \\
\hline pentanol & 4.3 & 3.8 & 3.3 & 3.0 & 340 & 3.0 \\
\hline
\end{tabular}

${ }^{a} \gamma_{2}^{S, \infty}$ is the estimated value of the activity coefficient, expressed at infinite dilution, above which phase splitting occurs, as dictated by eq 25 .

TABLE 6: Partial Molar Enthalpy of Several Alcohols at Infinite Dilution in RTIL $\left(H_{2}^{\mathrm{E}, \infty}\right)^{a}$

\begin{tabular}{lcl}
\hline \multicolumn{1}{c}{$(1)$} & $H_{2}^{\mathrm{E}, \infty}(\mathrm{J} / \mathrm{mol})$ & reference \\
\hline$[$ bmim $]\left[\mathrm{PF}_{6}\right]+$ ethanol & +10397 & this work \\
[bmim] $]\left[\mathrm{NTf}_{2}\right]+$ 2-methylpropanol & +13119 & this work \\
[emim] $\left[\mathrm{NTf}_{2}\right]+$ propanol & +7946 & 23 \\
[emim] $]\left[\mathrm{NTf}_{2}\right]+$ butanol & +9307 & 23 \\
[emim] $\left[\mathrm{NTf}_{2}\right]+$ pentanol & +11217 & 23
\end{tabular}

${ }^{a}$ In the case of the present work, this quantity is equal to $R d_{1}$ (see Table 4).

differ solely in their isotopic content is that, although $\chi(T)$ differs slightly from its isotopic counterpart, the critical value of $\chi$ that triggers phase separation remains the same upon isotopic substitution. ${ }^{19}$ Using the language of the adopted model in the current study, one is assuming that $r$ remains unchanged by isotopic substitution, which is the same as stating that the critical concentration is isotope insensitive (see eqs 21 and 22). All the experimental evidence accumulated so far, as well as estimations of the isotopic dependence of the critical concentration ${ }^{24}\left(\mathrm{~d} x_{\mathrm{c}}\right)$ $\mathrm{d} y \approx 10^{-4}$, where $y$ is the isotopic label, which changes from 0 to 1 ) indicate the validity, within experimental precision, of the aforementioned assumption. Therefore, upon applying eq 29 at critical conditions, one obtains

$$
\frac{\Delta T_{\mathrm{c}}}{T_{\mathrm{c}}} \approx \frac{-\Delta \delta \mu_{2}^{*}}{R T_{\mathrm{c}}}\left(\frac{1}{\chi_{\mathrm{c}}}\right)
$$

because $\Delta \mu_{2}^{*, \theta}=\Delta \mu_{2}^{*, 0}$. (See eq 14.) Note that eq 30 is only exact when the interaction parameter has the original FloryHuggins temperature dependence $\left(d_{\mathrm{o}}=d_{2}=0\right.$ in eq 9$)$. For the more general temperature dependence used in this work, while interpreting the phase diagrams (only $d_{2}=0$ ),

$$
\frac{\Delta T_{\mathrm{c}}}{T_{\mathrm{c}}}=\frac{-\Delta \delta \mu_{2}^{*}}{R T_{\mathrm{c}}} \frac{1}{\chi_{\mathrm{c}}-d_{0}}
$$

TABLE 7: $\mathrm{OH}(\mathrm{D})$ Mode Frequencies of Ethanol ${ }^{a}$

\begin{tabular}{lcrr}
\hline & $v_{\mathrm{a}}$ & $\nu_{\mathrm{b}}$ & \multicolumn{1}{c}{$v_{\mathrm{c}}$} \\
\hline liquid (OH) & 3330 & 1375 & 670 \\
gas (OH) & 3687 & 1249 & 0 \\
liquid (OD) & 2475 & 956 & 475 \\
gas (OD) & 2713 & 875 & 0
\end{tabular}

${ }^{a}$ From ref 26. All mode frequencies given in units of $\mathrm{cm}^{-1}$.

The parameter $d_{0}$ is intimately related to the symmetrical of the excess entropy of the mixture, ${ }^{5}$ because $T S^{\mathrm{E}}=H^{\mathrm{E}}-G^{\mathrm{E}}$ (see also eqs 9 and 10).

Note that, for molecules in the liquid state which are neither too small nor strongly associated, the second term of eq 27 is much greater than the first. For instance, Calado et al. ${ }^{25}$ have shown that, as one moves from $\mathrm{H}_{2} / \mathrm{D}_{2}$ to $\mathrm{CH}_{4} / \mathrm{CD}_{4}$ and to $\mathrm{C}_{6} \mathrm{H}_{6} /$ $\mathrm{C}_{6} \mathrm{D}_{6}$, the contributions to the excess free energy that result from the first (lattice modes) term and the second term are, respectively, in the same order of $94 \%-6 \%, 67 \%-33 \%$, and $14 \%-86 \%$. Also, upon applying the theory for the case of ethanol ( $\mathrm{OH}$ versus $\mathrm{OD})$, only the three modes that involve $\mathrm{OH}$ vibrations (stretching $(a)$, deformation $(b)$ in the $\mathrm{COH}$ plane, and out-of-plane vibration $(c)$ ) should contribute. Therefore, eq 27 can, in first approximation, be reduced (after combination with eq 31) to

$$
\begin{gathered}
-\Delta T_{\mathrm{c}}=\left(\frac{1}{\chi_{\mathrm{c}}-d_{0}}\right) \frac{1}{2}\left(\frac{h c}{k}\right)\left\{\left[\left(v_{i}^{\prime}-v_{i}\right)^{\circ}-\left(v_{i}^{\prime}-v_{i}\right)^{\infty}\right]_{a}-\right. \\
\left.\left[\left(v_{i}^{\prime}-v_{i}\right)^{\circ}-\left(v_{i}^{\prime}-v_{i}\right)^{\infty}\right]_{b}-\left[\left(v_{i}^{\prime}-v_{i}\right)^{\circ}-\left(v_{i}^{\prime}-v_{i}\right)^{\infty}\right]_{c}\right\}
\end{gathered}
$$

Assuming now a harmonic model for all the $\mathrm{O}-\mathrm{H}(\mathrm{D})$ modes and multiplying both members by $(-1)$ results in

$$
\begin{aligned}
\Delta T_{\mathrm{c}}=\left(\frac{1}{\chi_{\mathrm{c}}-d_{0}}\right) \frac{1}{2}\left(\frac{h c}{k}\right)\left[1-\left(\frac{m_{\mathrm{r}, \mathrm{OH}}^{\prime}}{m_{\mathrm{r}, \mathrm{OD}}}\right)^{1 / 2}\right]\left[\left(v_{\mathrm{OH}}^{\infty}-v_{\mathrm{OH}}^{\mathrm{o}}\right)_{a}+\right. \\
\left.\left(v_{\mathrm{OH}}^{\infty}-v_{\mathrm{OH}}^{\mathrm{o}}\right)_{b}+\left(v_{\mathrm{OH}}^{\infty}-v_{\mathrm{OH}}^{\mathrm{o}}\right)_{c}\right]
\end{aligned}
$$

where the $v$ terms are frequencies (expressed as wavenumbers) and the $m_{\mathrm{r}}$ terms are reduced masses for the $\mathrm{O}-\mathrm{H}$ vibration $\left(1 / m_{\mathrm{r}}=1 / m(\mathrm{H}(\mathrm{D}))+1 / m(\mathrm{O})\right)$. Equation 33 provides us with the possibility of predicting the shift in the critical temperature of demixing from $\mathrm{O}-\mathrm{H}$ vibrations of ethanol when the molecule is transferred from its pure state to the infinitely diluted state in the RTIL. This spectroscopic information is not available. Nevertheless, assignments of the $\mathrm{OH}$ mode frequencies ${ }^{26}$ in ethanol (liquid) and ethanol (gas) do exist, as well as in its isotopic counterpart (see Table 7). In fact, the low-frequency out-of-plane vibration (denoted as $c$ ) corresponds to a hindered rotation of the $\mathrm{OH}$ group about the $\mathrm{C}-\mathrm{O}$ axis of the molecule. This is why it is assigned a zero value in the gas phase (free rotation). In contrast, in a condensed phase (such as that of liquid 
infinite dilution in the RTIL), its frequency should approach that of the pure liquid, and, thus, should not contribute significantly to eq 33 . The other two frequencies ( $a$ and $b$ ) are expected to suffer shifts between pure liquid and liquid at infinite dilution in the RTIL commensurate with those between pure liquid and pure gas. For vibration $a$, we find a blue shift of approximately $+350 \mathrm{~cm}^{-1}$ upon vaporization, whereas for vibration $b$, there is a red shift of approximately $-125 \mathrm{~cm}^{-1}$ (see Table 7). This equates to, in both cases, an effect upon phase change (pure liquid to gas) of $\sim 10 \%$. Assuming that both vibrations $a$ and $b$ also shift equally (in percentage) upon liquid infinite dilution in the RTIL, then, using eq 33, one finds that, although a red shift of $-15 \mathrm{~cm}^{-1}$ for vibration $b$ is obtained, the most phase-sensitive frequency (vibration $a$ ) suffers a blue shift of $+35 \mathrm{~cm}^{-1}$. This value should be interpreted as the limit of the minimum effect, because, in the aforementioned calculation, we have neglected the possible contribution of two other librational (external, of the entire molecule) modes, corresponding to hindered rotations that are linked to hydrogen bonding. These vibrational modes are expected to suffer a red shift upon transfer from " $O$ " to " $\infty$ "; similarly they do so upon the transfer from a pure liquid state to the ideal-gas state.

Acknowledgment. The authors are grateful to Dr. Gábor Jancsó for providing frequency assignments of $\mathrm{OH}$ in ethanol (H/D). This work was financially supported by Fundação para a Ciência e Tecnologia, Portugal, under Contract Nos. POCTI/ EQU/34955 and POCTI/EQU/ 35437. V.N.-V. and J.M.S.S.E. are grateful to Fundação para a Ciência e Tecnologia for doctoral fellowships.

\section{References and Notes}

(1) (a) Welton, T. Chem. Rev. 1999, 99, 2071. (b) Holbrey, J. D.; Seddon, K. R. Clean Prod. Process. 1999, 1, 223. (c) Brennecke, J. F.; Maginn, E. J. AIChE J. 2001, 47, 2384. (d) Huddleston, J. G.; Visser, A. E.; Reichert, W. M.; Willauer, H. D.; Broker, G. A.; Rogers, R. D. Green Chem. 2001, 3, 156. (e) Seddon, K. R.; Stark, A.; Torres, M.-J. Pure Appl. Chem. 2000, 72, 2275. (f) Anthony, J. L.; Maginn, E. J.; Brennecke, J. J. Phys. Chem. B 2002, 106, 7315. (g) Morrow, T. I.; Maginn, E. J. J. Phys. Chem. B 2002, 106, 12807. (h) Domanska, U.; Bogel-Lukasik, E.; BogelLukasik, R. J. Phys. Chem. B 2003, 107, 1858.

(2) Visser, A. E.; Swatloski, R. P.; Reichert, W. M.; Griffin, S. T.; Rogers, R. D. Ind. Eng. Chem. Res. 2000, 39, 3596.

(3) Najdanovic-Visak, V.; Esperança, J. M. S. S.; Rebelo, L. P. N.; Nunes da Ponte, M.; Guedes, H. J. R.; Seddon, K. R.; Szydlowski, J. Phys. Chem. Chem. Phys. 2002, 4, 1701.

(4) (a) Fadeev, A. G.; Megher, M. M. Chem. Commun. 2001, 295. (b) Freemantle, M. Chem. Eng. News 2001, 79, (14), 57.

(5) (a) Rebelo, L. P. N. Phys. Chem. Chem. Phys. 1999, 1, 4277. (b) de Sousa, H. C.; Rebelo, L. P. N. J. Polym. Sci. B: Polym. Phys. 2000, 38, 632 .
(6) (a) Bigeleisen, J. J. Chem. Phys. 1961, 34, 1485. (b) Jancsó, G.; Rebelo, L. P. N.; Van Hook, W. A. Chem. Rev. 1993, 93, 2645. (c) Van Hook, W. A.; Rebelo, L. P. N.; Wolfsberg, M. J. Phys. Chem. A 2001, $105,9284$.

(7) (a) Gordon, C. M.; Holbrey, J. D.; Kennedy, R.; Seddon, K. R. J. Mater. Chem. 1998, 8, 2627. (b) Bonhôte, P.; Dias. A.-P.; Armand, M.; Papageorgiou, N.; Kalyanasundaram, K.; Gratzel, M. Inorg. Chem. 1996, 35,1168 . 355.

(8) de Sousa, H. C.; Rebelo, L. P. N. J. Chem. Thermodyn. 2000, 32,

(9) Szydlowski, J.; Rebelo, L. P. N.; Van Hook, W. A. Rev. Sci. Instrum. 1992, 63, 1717.

(10) Rebelo, L. P. N.; Visak, Z. P.; de Sousa, H. C.; Szydlowski, J.; Gomes de Azevedo, R.; Ramos, A. M.; Najdanovic-Visak, V.; Nunes da Ponte, M.; Klein, J. Macromolecules 2002, 35, 1887.

(11) (a) Rabinovich, I. B. Influence of Isotopy on the Physicochemical Properties of Liquids; Consultant Bureau: New York, 1970; Chapter 12. (b) Fenby, D.; Kooner, Z. S.; Khurma, J. R. Fluid Phase Equilib. 1981, 7, 327. (c) Szydlowski, J. J. Mol. Struct. 1994, 321, 101. (d) Salvi, M. V.; Van Hook, W. A. J. Phys. Chem. 1990, 94, 7812.

(12) (a) Wilson, K. G. Phys. Rev. B 1971, B4, 3174, (b) Greer, S. C. Phys. Rev. A 1976, A14, 1770. (c) Singh, R. R.; Van Hook, W. A. J. Chem. Phys. 1987, 87, 6088 .

(13) (a) Swatloski, R. P.; Visser, A. E.; Reichhert, W. M.; Broker, G. A.; Farina, L. M.; Holbrey, J. D.; Rogers, R. D. Chem. Commun. 2001, 2070. (b) Swatloski, R. P.; Visser, A. E.; Reichhert, W. M.; Broker, G. A.; Farina, L. M.; Holbrey, J. D.; Rogers, R. D. Green Chem. 2002, 4, 81.

(14) Anthony, J. L.; Maginn, E. J.; Brennecke, J. F. J. Phys. Chem. B 2001, 105, 10942.

(15) Marsh, K. N.; Deev, A. V.; Wu, A. C.-T.; Tran, E.; Klamt, A. Korean J. Chem. Eng., 2002, 19, 357.

(16) Wu, C.-T.; Marsh, K. N.; Deev, A. V.; Boxall, J. A. J. Chem. Eng. Data 2003, 48, 486.

(17) Heintz, A.; Lehmann, J. K.; Wertz, C. J. Chem. Eng. Data 2003, 48,472 .

(18) Schneider, G. Ber. Bunsen-Ges. Phys. Chem. 1966, 70, 497.

(19) Visak, Z. P.; Rebelo, L. P. N.; Szydlowski, J. J. Phys. Chem. B 2003, 107, 9837-9846.

(20) (a) Kamide, K. Thermodynamics of Polymer Solutions; Elsevier: Amsterdam, 1990; Chapter 1. (b) Rätzsch, M. T.; Kehlen, H. Prog. Polym. Sci. 1989, 14, 1. (c) Luszczyk, M.; Van Hook, W. A. Macromolecules 1996, 29, 6612. (d) Enders, S.; de Loos, T. W. Fluid Phase Equilib. 1997, 139, 335.

(21) Rebelo, L. P. N.; Najdanovic-Visak, V.; Visak, Z. P.; Nunes da Ponte, M.; Troncoso, J.; Cerdeiriña, C. C.; Romani, L. Phys. Chem. Chem. Phys. 2002, 4, 2251.

(22) Rebelo, L. P. N., et al., to be submitted to Phys. Chem. Chem. Phys.

(23) Heintz, A.; Kulikov, D. V.; Verevkin, S. P. J. Chem. Eng. Data 2002, 47, 894.

(24) Singh, R. R.; Van Hook, W. A. J. Chem. Phys. 1987, 87, 6097.

(25) Calado, J. C. G.; Jancsó, G.; Lopes, J. N. C.; Markó, L.; Nunes da Ponte, M.; Rebelo, L. P. N.; Staveley, L. A. K. J. Chem. Phys. 1994, 100, 4582.

(26) Jancsó, G. KFKI Kozl. 1966, 14, 219. 